\title{
Infection by Helicobacter pylori in Nova Iguaçu City, Rio de Janeiro Province, Brazil
}

\author{
Pedro Vinhaes Braga da Silva ${ }^{1}$, Victoria Luiza Pacini ${ }^{1}$, Antonio Neres Norberg ${ }^{2,3,4,}$, \\ ${ }^{1}$ Host-Pathogen Interaction Department, Medicine Academic of Souza Marques Medicine School - FTESM, Rio de Janeiro, Brazil \\ ${ }^{2}$ Host-Pathogen Interaction Department, Souza Marques Medicine School - FTESM, Rio de Janeiro, Brazil \\ ${ }^{3}$ Pathology Department, UNIABEU/PROBIN University Center, Belford Roxo, Brazil \\ ${ }^{4}$ Public Health Department, Manhuaçu Management Sciences School - FACIG, Manhuaçu, Brazil
}

\section{Email address:}

pedro_vinhaes@hotmail.com (P. V. B. da Silva), victorialuizapacini@gmail.com (V. L. Pacini), antonionorberg@gmail.com (A. N. Norberg) ${ }^{*}$ Corresponding author

\section{To cite this article:}

Pedro Vinhaes Braga da Silva, Victoria Luiza Pacini, Antonio Neres Norberg. Infection by Helicobacter pylori in Nova Iguaçu City, Rio de Janeiro Province, Brazil. European Journal of Clinical and Biomedical Sciences. Vol. 3, No. 1, 2017, pp. 19-23.

doi: $10.11648 /$ j.ejcbs.20170301.14

Received: January 19, 2017; Accepted: February 14, 2017; Published: March 1, 2017

\begin{abstract}
Helicobacter pylori infection is an important factor in the development of gastric carcinogenesis, but only a fraction of infected patients will develop gastric cancer. The aim of this research is to investigate the prevalence of $H$. pylori infection among dyspeptic patients of Nova Iguaçu city, province of Rio de Janeiro, Brazil. The research design is observational, retrospective and cross-sectional. The universe consisted of 56 patients of both genders aged over 25 years. Between January 2015 and July 2016, fragments of the lesions suggestive of $H$. pylori infection were collected through digestive endoscopy. The biopsy specimens were analyzed in a pathological anatomy laboratory and the validation of the infection was confirmed by the morphotintorial characteristics of the bacteria and biological tests: arched Gram negative bacilli through anatomopathological examination and positive urease test. Among patients suspected of $H$. pylori infection, 12 (21.4\%) were positive. The infection was confirmed in dyspeptic patients in the studied region. The prevalence is below the global values, where $50 \%$ of the population is a pathogenous carrier. There were no significant differences between infection and gender correlation. Positivity was higher in people between the ages of 41 and 50 years.
\end{abstract}

Keywords: Helicobacter pylori, Gastric Mucosa, Dyspepsia, Cancer

\section{Introduction}

Gastritis caused by Helicobacter pylori is a chronic inflammatory disease of the antrum and the body of the stomach. This bacterium is considered the most frequent etiologic agent in patients with gastritis in the United States of America and is associated with peptic ulcer disease of the stomach and duodenum. Species of the genus Helicobacter presents as arched Gram negative rod cells with a polar flagella and produces a similar movement to the corkscrew. This bacterium was isolated from several populations in the world and the prevalence of infection by this microorganism increases with age around 60 years. Serological studies show that around $50 \%$ of the world population has serological evidence of infection by this bacterium. Households with $H$. pylori infection suggests the possibility of person-to-person trans- mission and there is evidence that $2 / 3$ of the infected people have histopathological signs of chronic gastritis $[1,2]$.

The reasons for accepting $H$. pylori as a pathogen responsible for chronic gastritis rather than a simple commensal which colonizes of the injured gastric mucosa are: 1) gastritis is established in healthy people after ingestion of the bacterium; 2) H. pylori is attached to the epithelium in areas of chronic gastritis and absent over the unaffected areas of the gastric mucosa; 3) eradication of infection with bismuth treatment or antibiotics cures gastritis; 4) Anti-H. Pylori antibodies are detected in people with chronic gastritis; 5) the increasing prevalence of $H$. pylori infection with age is in line with that of chronic gastritis. The virulence of this bacterium is related to the island of pathogenicity CAG (Cytotoxin Associated Gene Pathogenicity Island - CAG-PAI), a $40 \mathrm{~kb}$ DNA segment which has 31 genes. This indicator of viru- 
lence is associated with duodenal ulcer and gastric cancer. In another separate region of the genome, it holds the Vacuolation Cytotoxin Gene (vac-A), which is also associated with duodenal ulcer disease. Chronic H. pylori infection is a predisposing factor to the appearance of the lymphoid MALT (lymphoid tissue associated with the mucosa) of the stomach. The arched rods of the bacteria are found on the surface of epithelial cells and gastric follicles. Active gastritis is characterized by the presence of polymorphonuclear leukocytes in the glands, as well as in their lights, and through a greater number of plasma cells and lymphocytes in the lamina propria. Lymphoid hyperplasia with germinal centers is frequent $[1,2,3]$.

It is possible that infection caused by $H$. pylori should be the most common chronic infection in the world [4]. The prevalence of the bacteria in the general population is high, especially in developing countries, where infection is usually acquired in childhood $[5,6]$. It is estimated that at least $50 \%$ of the world population is infected by these bacteria [7].

The importance of $H$. pylori, however, surpasses the high prevalence of infection. Its importance as the main etiological agent of chronic gastritis and the cause of gastric and duodenal ulcers has changed the concepts in gastroenterology, indicating an infectious cause for these diseases. Later, its characterization as a carcinogen agent, linked to the development of gastric cancer and MALT (Mucosa-associatedlymphoid-tissue) lymphoma in the stomach, further increased the knowledge base about the pathogenic potential attributed to this bacterium [8].

About the clinical manifestations, the basic and initial clinical expression of $H$. pylori action in the gastric mucosa is the development of gastritis. Its acute phase, with large infiltration of polymorphonuclear neutrophils in the mucosa, is followed in the chronic phase, where the lamina propria is full of lymphocytes and neutrophils. It reflects the degree of activity of chronic gastritis [8].

At the beginning of the infection the $H$. pylori predominantly affects the gastric antrum. Antral gastritis causes a reduction of the production of somatostin, leading to hypergastrinemia and increased acid secretion. Patients with this condition would therefore should be at greater risk of developing duodenal ulcers [8,9]. Some of these patients with antral gastritis evolves to the atrophy of the affected mucosa. This represents a loss of the gastrin-producing $\mathrm{G}$ cell population and, therefore, the reduction of acid production by the parietal cells of the gastric body $[1,8]$. With a less acid stomach, $H$. pylori ascends from the antrum to the body and, over time, the inflammatory reaction perpetuated in the body can also cause mucosal atrophy in this region, characterizing the atrophic gastritis. These patients would be at greater risk of developing gastric ulcer, in addition, the glandular epithelium is replaced with areas of intestinal metaplasia, which increases the chance of developing gastric adenocarcinoma [10]. Another metaplasia that showed association with $H$. pylori infection is MALT lymphoma. This B-cell lymphoma appears surrounding the reactive lymphoid follicles that arise in chronic gastritis, infiltrating and injuring the glandular epi- thelium (lymphoepithelial lesion). There are evidences that $H$. pylori enlists MALT-forming lymphoid cells and these cells accumulates mutations, transforming MALT into malignant lymphoma $[8,11]$.

Considering the pathogenicity of the bacterium in question as an important pathogen and inducer of malignant lesions, this research have the aim to investigate the prevalence of $H$. pylori infections among the population of the city of Nova Iguaçu, province of Rio de Janeiro, Brazil.

\section{Material and Methods}

The research design is individualized, observational, transversal and retrospective type. The studied population consisted of patients of both genders with ages above 25 years with dyspeptic symptoms. The inclusion criteria were: to live in the city of Nova Iguaçu, province of Rio de Janeiro, Brazil, accept to be voluntary to digestive endoscopy, not to be in use of medications. Between January 2015 and July 2016, fragments of suggestive lesions of Helicobacter pylori infection were collected by gastric biopsy through digestive endoscopy. 56 patients of both genders participated as patients in the research. The patients were attended at the Dr. Vanderlei Pacini Clinic, city of Nova Iguaçu. The samples were submitted to biopsy and examined at the Laboratory of Clinical Pathology Dr. Eliel Figueiredo. The diagnosis of $H$. pylori infection was confirmed by morphotinorial characteristics of the bacterium and biological tests: Gram negative arched bacilli at anatomopathological examination and positive urease test.

\section{Results}

Among the 56 patients that constituted the total number of examined cases, 12 presented $H$. pylori infection, which determined a prevalence of $21.4 \%$.

Table 1. Prevalence of Helicobacter pylori among the patients studied in the municipality of Nova Iguaçu according to the amount of bacilli per microscopic field.

\begin{tabular}{lll}
\hline Helicobacter pylori & Simple frequency & Percentual frequency \\
\hline Negative biopses & 44 & 78,57 \\
Modest quantity & 4 & 7,14 \\
Average quantity & 5 & 8,92 \\
Large quantity & 3 & 5,35 \\
Total & 56 & 100 \\
\hline
\end{tabular}

Source: Dr. Vanderlei Pacini Clinic

Table 2. Prevalence of Helicobacter pylori according to the gender of the patients examined in the city of Nova Iguaçu.

\begin{tabular}{lll}
\hline Gender & Simple frequency & Percentual frequency \\
\hline Men & 5 & 41,66 \\
Women & 7 & 58,44 \\
Total & 12 & 100 \\
\hline
\end{tabular}

Source: Dr. Vanderlei Pacini Clinic 
Table 3. Cases diagnosed with Helicobacter pylori infection according to the age group of the patients examined in the city of Nova Iguaçu.

\begin{tabular}{lll}
\hline Age group & Simple frequency & $\begin{array}{l}\text { Percentual frequency among } \\
\text { positive cases }\end{array}$ \\
\hline $25-30$ & 1 & 8,33 \\
$31-40$ & 3 & 25 \\
$41-50$ & 7 & 58,44 \\
$>50$ & 1 & 8,33 \\
\hline
\end{tabular}

Source: Dr. Vanderlei Pacini Clinic

\section{Discussion}

According to Del Valle et al. [5], Coura [8] and Coelho [12], Helicobacter pylori infection has a worldwide distribution and manifests itself differently in developed and developing countries. At the developed countries, the mean prevalence is prevalence is less than $40 \%$, while in the developing countries, values between $80 \%$ and $90 \%$ of positivity are registered. According to these authors, in Brazil the prevalence rate varies among different regions according to the social profile of the community. There are evidences that social factors such as educational level and family income are important variables to the risk of infection by this bacterium. We believe that other factors influence results in the population of Nova Iguaçu, where the rate of development is low, but the levels of $H$. pylori infection are lower than other studied communities and the relationship between social conditions and infection rates can't be verified.

According to Parkin et al. [13] and Mueller et al. [14], gastric cancer is considered the second cause of cancer deaths in the world, and these authors considered that almost $2 / 3$ of the these cases occur in developing countries. A significant advance in the etiology of gastric cancer was the identification of the $H$. pylori bacterium and its association with the gastric carcinogenesis process. These authors also considered that there is considerable heterogeneity among populations regarding the risk of developing gastric cancer associated with H. pylori infection. In this way, the researchers Guy et al. [15] found that in populations with a high prevalence of $H$. pylori infection, only a fraction of them will develop gastric cancer. Among the population with dyspepsia studied in the city of Nova Iguaçu, only $21.4 \%$ presented $H$. pylori infection. These results are lower than those found in the city of Fortaleza, Ceará state, where $62.9 \%$ of the population had positive results for the presence of this bacterium [16]. This result contrasts with the obtained in the population of Nova Iguaçu, where the younger age group presented lower levels of $H$. pylori infection.

According to Rubin et al. [1], Kumar et al. [2] and Bravo et al. (2003), gastric ulcer is a recurrent lesion most frequently diagnosed in middle-aged and elderly adults, often associated to $H$. pylori infection. The disease may manifest at the first time in young adults and may progress to chronicity or spontaneously heal over a period of weeks or months of active disease, with or without treatment. Considering these facts, our opinion is that the spontaneous cure of the disease is related to the biological characteristics of the infectious etiological agent that could be related to bacillus genes associated with its virulence, as well as the competence of the immune system of the infected people.

Fábio-Parada et al. [18] investigated the prevalence of $H$. pylori infection in pediatric patients infected with Human Immunodeficiency Virus (HIV) patients hospitalized in health care services of Guatemala. The research involved 40 children of both genders between 3 and 12 years of age. The result showed a positivity of $35 \%$, with a higher incidence among boys ( $47 \%$ of cases). The highest incidence was recorded between 7 and 8 years, with $66.7 \%$ of the cases. Our research revealed a positivity rate of $21.4 \%$ of immunocompetent adults of both genders, obtaining a lower rate than the prevalence among immunocompromised children with $H$. pylori.

A research of $H$. pylori infection in dyspeptic patients attended at the Hospital Militar Principal of Luanda, Angola, was performed by Rosa-Belmiro [19]. At the hospital level, the researcher chose for high digestive endoscopy method to collect biopsies of the gastric mucosa. The biopsied fragments were sent for anatomopathological and bacteriological examination. Among the 254 patients evaluated, 148 (58.27\%) revealed the presence of $H$. pylori in their tissues, and 106 $(41.73 \%)$ were negative. The rates found in Luanda are higher than those found in Nova Iguaçu, where the socioeconomic conditions of this country can be pointed as one of the important variables for this high prevalence index.

Gastric adenocarcinoma reaches high incidence rates in eastern countries, including China and Japan, especially when compared with rates recorded in Western countries. The incidence of gastric cancer was $2.9 \%$ in 1246 Japanese patients with $H$. pylori dyspepsia who were followed prospectively and no cases in $280 \mathrm{H}$. pylori-negative patients. Studies conducted by several researchers have demonstrated an association between $H$. pylori infection and gastric lesions as precursors of neoplasias [14]. In our research of 56 dyspeptic patients from the city of Nova Iguaçu, 12 (21.4\%) were positive for $H$. pylori but in none of them malignant lesions were diagnosed. We did not investigate virulence markers of $H$. pylori strains in our research, but the absence of carcinogenic lesions suggests that the predominant strain in the region is of less virulent among the population examined in Nova Iguaçu.

The prevalence of $H$. pylori in symptomatic patients attended at the Rebagliati Clinic Group (EsSalud) in Lima, Peru, from 2010 to 2013 was studied by Contreras et al. [20]. 1711 patients were investigated in this research. The results showed that the overall prevalence of $H$. pylori infection was 45.5\% (IC: 95\%: 43.17-47.89), being a higher rate in women than in men $(47.1 \%$ versus $42.1 \%, p=0.056)$, with a positive result in $201(51.1 \%)$ of women of childbearing age. There were significant differences by age groups between infected and non-infected (44 versus $39, \mathrm{p}<0.05$ ) with association according to the age and the presence of H. pylori $(\mathrm{p}<0.001)$. The prevalence found in the children was $36.6 \%$. The authors concluded that the prevalence of $H$. pylori in the studied population was similar in both genders and was related to age. 
Capote et al. [21] studied the dyspepsia caused by H. pylo$r i$ in patients attending gastroenterology consultations at the Hospital General Docente Abel Santamaría Cuadrado in Pinar del Río, Cuba, with suggestive symptoms of upper digestive tract disease from January to June. 2011. The studied population consisted of 204 patients, undergoing gastroduodenoscopy with a gastric biopsy. The biopsies fragments were stained with Ziehl Neelsen method for the search of $H$. pylori. The results showed that among the 240 patients examined, $204(85 \%)$ were infected, with male predominance. The chronic gastritis was the most associated gastric alteration with the infection. Epigastralgia was the most frequent symptom and $44.6 \%$ of cases evolved unsatisfactorily. The rate found by these authors is above the rate of $21.4 \%$ diagnosed in dyspeptic patients in the city of Nova Iguaçu, also differing in the prevalence by gender.

Leyva et al. [22] conducted a descriptive and retrospective study involving 989 patients with endoscopic diagnosis of chronic gastritis, whose biopsies were performed in the department of pathological anatomy in the city of Palma Soriano, Santiago de Cuba Province, from 2008 to 2014. To find the incidence of $H$. pylori infection, considering the variables: age, gender, kinds of gastritis, presence of the microorganisms and its association with malignant metaplasias. The results showed that the disease affected mostly the age group of 40 to 49 years $(26.7 \%)$ and female gender $(69.0 \%)$. The superficial gastritis was diagnosed in $58.8 \%$, and the bacterium was found in $70.5 \%$ of the samples. Only $0.5 \%$ were associated with malignant neoplasms. Among the participants in our research, $21.4 \%$ of the biopsied patients were positive for $H$. pylori, but there were no cases of malignancy observed.

The prevalence and pathology of H. pylori in gastric biopsies in Colombia was studied by Bravo et al. [17] These authors conducted a comparative research that describes the prevalence of $H$. pylori and the associated alterations of gastric mucosa in symptomatic people coming from regional capitals of Colombia. The research involved the registries of 16 pathology laboratories of regional hospitals of the country. They reviewed the results of all histopathological records performed in 1997, with a total of 86243 patient records. In order to know the reality of the gastric diseases and the incidence of them, variables as age, gender, kind of procedure (biopsy or gastrectomy) and classification of the histopathological diagnosis were separately evaluated. With the obtained information, the authors described these characteristics according to different regions of Colombia. The prevalence of $H$. pylori was $69.1 \%$. The most frequent diagnosis was chronic non-atrophic gastritis in $36.4 \%$. The prevalence of cancer was $9.3 \%$. The authors concluded that $H$. pylori infection was the gastric pathology with the highest morbidity in Colombia, and its distribution shows that there are significant geographical variations among regional populations. We agree with the authors that $H$. pylori infection is the most frequent cause of gastric pathology morbidity, fact also observed in our research.

\section{Conclusion}

From the analysis of the results, it can be concluded that $H$. pylori infection was found in dyspeptic patients that lives in Nova Iguaçu city. The prevalence of infection is below the global mean values, where $50 \%$ of the population is a carrier. There was no statistically significant difference in the distribution of the infection by gender. Individuals in the 41-50 age group are more susceptible to $H$. pylori infection.

\section{References}

[1] Rubin E, Gorstein F, Rubin R, Schwarting R, Strayer D. Rubin Patologia. Bases Clínicopatológicas da Medicina. Guanabara Koogan, Rio de Janeiro, 2006.

[2] Kumar V, Abbas AK, Aster JC. Patologia. Bases Patológicas das Doenças. Elsevier, Rio de Janeiro, 2016.

[3] Porth CM, Matfin G. Fisiopatologia. Guanabara Koogan, Rio de Janeiro, 2010.

[4] Go MF, Crowe SH. Virulence and pathogenicity. Clinics of North America, W. B. Saunders, Philadelphia, 2000.

[5] Del Valle J, Cohen H, Laine L, Scheiman JM. Acid peptic disorders. In: Yamada T, Alpers DH, Laine L, Owiang C, Powell DW (eds). Textbook of Gastroenterology, Philadelphia, 1999.

[6] Murray PR, Rosenthal KS, Pfaller MA. Microbiologia Médica. Elsevier, Rio de Janeiro, 2014.

[7] Everhart JE. Recent developments in epidemiology of Helicobacter pylori. Gastroenterol Clin North America 2000; 29: 559-578.

[8] Coura JR. Dinâmica das Doenças Infecciosas e Parasitárias. Guanabara Koogan, Rio de Janeiro, 2013.

[9] Moss SF, Legon S, Davies J, Calam J. Cytokine gene expression. In Helicobacter pylori associated antral gastritis. Gut, 1995; 35: 1567-1570.

[10] McColl KEL, Murray LS, Gillen D. Randomized trial of endoscopy with non-invasive $H$. pylori testing alone in the management of dyspepsia. BMJ 2002; 324: 999-1002.

[11] Wotherspoon AC, Hortiz-Hidalgo C, Falzon MR, Isaacson PG. Helicobacter pylori associated with gastritis and primart B. cell gastric lymphoma. Lancet 1991; 338: 1575-1576.

[12] Coelho LG, Leon-Barúa R, Quiglev EM. Latin-American consensus conference on Helicobacter pylori infection. Am J Gastroenterol 2000; 95: 2688-2691.

[13] Parkin DM, Bray F, Ferlay J, Pisani J. Global cancer and statistics. CA Cancer J Clin 2005; 55: 74-108.

[14] Mueller LB, Fagundes RB, Moraes CC, Rampozzo A. Prevalência da infecção por Helicobacter pylori e das lesões precursoras do câncer gástrico em pacientes dispépticos. Arq Gastroenterol 2007; 44 (2): 93-98.

[15] Guy DE, Lynette YL, Julie EB, Harry H, Nicholas JT. Association of Helicobacter pylori infection with gastric carcinoma: a meta-analysis. Am J Gastrenterol 1999; 94: 2372-2379. 
[16] Rodrigues MN, Queiroz DMM, Rodrigues MT, Rocha AMC, Luz CR, Braga LBC. Prevalence of Helicobacter pylori infecion in Fortaleza, northeastern Brazil. Rev Saúde Pública 2005; 39 (5): 847-849.

[17] Bravo LE, Cortés A, Carrascal E, Jamarillo R, Abdon LSG, Bravo E et al. Helicobacter pylori: patologia y prevalencia en biopsias gástricas en Colombia. Comb Med 2003; 34: 124131.

[18] Fábio-Parada JL, Júlio-Linhares OO, Ana-Orantes FP, GuidoAndreatta AS, Andrea-Sandoval LM, Fernando-Gutierréz LM et al. Prevalencia de Helicobacter pylori en un grupo de pacientes pediatricos infectados por el virus de la inmunodeficiencia humana. Rev Ciencia Tecnol y Salud 2015; 2 (2): 135-139.

[19] Rosa-Belmiro F. Infecção por Helicobacter pylori em populações de Angola [doctoral thesis]. Nova Medical School. http://hnd.handle.net/10362/15725.

[20] Contreras OC, Quispe JM, Goñi HB, Mendoza AC, Calderón EG, Moscol MD et al. Prevalencia de Helicobacter pylori en pacientes sintomáticos de consulta externa de la Red Rebagliati (EsSalud), Lima, Peru, en el período 2010-2013. Rev Gastroenterol Peru 2016; 36 (1): 49-55.

[21] Capote EG, Ramírez EC, Garcell HG. Infección por Helicobacter pylori en pacientes atendidos en consulta de gastroenterología. Rev Ciencias Médicas 2014; 18 (3): 453462 .

[22] Leyva LM, Dalmau NB, Heal ST, Vasquez AA, Chang NVF. Infección por Helicobacter pylori en el municipio de PalmaSoriano durante el período 2008-2014. MEDSAN 2016; 20 (11): 2339-2344. 